\title{
Journal of Stem Cell Research
}

Genesis-JSCR-1(2)-12

Volume 1 | Issue 2

Open Access

\section{The Effects of Stem Cells Plus Lithium on the Recovery of Spinal Cord Injury}

\section{Keeghan Andrews and Vincent S Gallicchio*}

Department of Biological Sciences, College of Science, Clemson University, Clemson, South Carolina, USA

"Corresponding author: Vincent S Gallicchio, Department of Biological Sciences, College of Science, Clemson University, Clemson, South Carolina, USA

Citation: Andrews K, Gallicchio VS. (2020) The Effects of Stem Cells Plus Lithium on the Recovery of Spinal Cord Injury. J Stem Cell Res. 1(2):1-15.

Received: December 08, 2020 | Published: December 25,2020
Copyright $^{\odot} 2020$ by Andrews K, et al. All rights reserved. This is an open access article distributed under the terms of the Creative Commons Attribution License, which permits unrestricted use, distribution, and reproduction in any medium, provided the original author and source are credited.

\section{Abstract}

Spinal cord injury $(\mathrm{SCl})$ is damage to the spinal cord that leads to sudden loss of motor, sensory, and autonomic function below the level of the injury. The annual incidence of $\mathrm{SCl}$ in the United States is approximately 12,500 new cases each year. Stem cell transplant procedures show promising potential as a treatment for $\mathrm{SCl}$. Lithium has been used to treat other medical diagnoses including depression, stroke, and additional neurodegenerative diseases. Researchers have investigated the effectiveness of combining stem cells and lithium in animal models and also started to explore options with human subjects. Researchers believe the use of stem cells combined with lithium may offer alternative options for patients with $\mathrm{SCl}$.

\section{Keywords}

Spinal cord injury; Stem cells; Lithium; Treatment

\section{Abbreviations}

AIS: American Spinal Injury Association Impairment Scale; CNS: Central Nervous System; ESCs: Embryonic stem cells; FDA: Food and drug administration; GSK3B - Glycogen synthetase kinase 3-B; 
hESCs: Human embryonic stem cells; hNSCs: Human neural stem cells; hUCB-SCs: Human umbilical cord blood mesenchymal stem cell; LiCl: Lithium chloride; MSCs: Mesenchymal stem cells; NPCs: Neural progenitor cells; NSCs: Neural stem cells; SCl: Spinal cord injury; SCs: Schwann cells; UCB-MNC Umbilical cord blood derived mononuclear cell

\section{Introduction}

Spinal cord injury (SCl) occurs from damage to the spinal cord resulting ina sudden loss of motor, autonomic, and sensory function below the level of the injury [1-5]. The global incidence of $\mathrm{SCl}$ is estimated at 10 cases per 100,000 people which results in over 700,000 newly diagnosed cases each year throughout the world. The annual incidence of spinal cord injury observed in the United States is approximately 40 cases per million population, or 12,500 new cases of $\mathrm{SCl}$ each year. Since the 1970 s, the average age of spinal cord injury has increased from 29 years to 42 years currently. Approximately $80 \%$ of new $\mathrm{SCl}$ cases are males [1,2,6-9]. Primary causes for $\mathrm{SCl}$ include: vehicle crashes $38 \%$, falls $30 \%$, act of violence including gunshot wounds $14 \%$, sports related activities $9 \%$, medical/surgical 5\%, and other $4 \%$. Neurological level and extent of lesion include:45\% incomplete tetraplegia, $21 \%$ incomplete paraplegia, $20 \%$ complete paraplegia, and $14 \%$ complete tetraplegia. Financial impact for health care and living expenses for an individual with $\mathrm{SCl}$ range from $\$ 1,064,716$ for the initial year for a patient with high tetraplegia and an estimated lifetime cost of $\$ 2,596,329[2,8,9,10]$.

$\mathrm{SCl}$ pathophysiology has two phases, a primary phase and secondary phase. The primary $\mathrm{SCl}$ phase occurs in a short period immediately after the injury, usually within 4 hours [3]. SCl primary phase includes the initial compression or shearing of the spinal cord tissue causing hemorrhage, disruption of the blood vessels, cell membranes, and axons. This event leads to compromise of neural function $[2,10]$. The primary phase is characterized by displacement of the anatomical structures within the spinal cord that leads to disruption of descending neuronal pathways $[3,11,12]$.

$\mathrm{SCl}$ secondary phase occurs a few minutes to several days after the primary injury [3]. Secondary SCl phase relates to progressive inflammatory, ischemic, and apoptotic sequence following the initial injury $[10,13]$. The secondary phase is characterized by delayed period of tissue destruction involving vascular dysfunction, electrolyte shifts, ischemia, edema, excitotoxicity, inflammation, free radical production, and restrained apoptotic cell death $[2,11]$. The spinal cord injury leads to the formation of a glial scar causing raised neuron and oligodendrocyte cell death that result in increased axon growth inhibitory factors within the site of the injury $[2,3,4,14]$. Inflammation is an important factor in both early and chronic spinal cord injury stages. Macrophages, neutrophils and T-cells migrate in from peripheral circulation and are activated. Macroglia, which are usually in the spinal cord, are also activated. Microglia and macrophages both remove dead cells and debris via phagocytosis $[3,15]$. Neurological recovery after $\mathrm{SCl}$ is restricted due to the limited capacity of the adult spinal cord to restore the lost neurons and oligodendrocytes, remyelinate axons, and re-establish neural functional connections $[11,16]$ (Figure 1). 


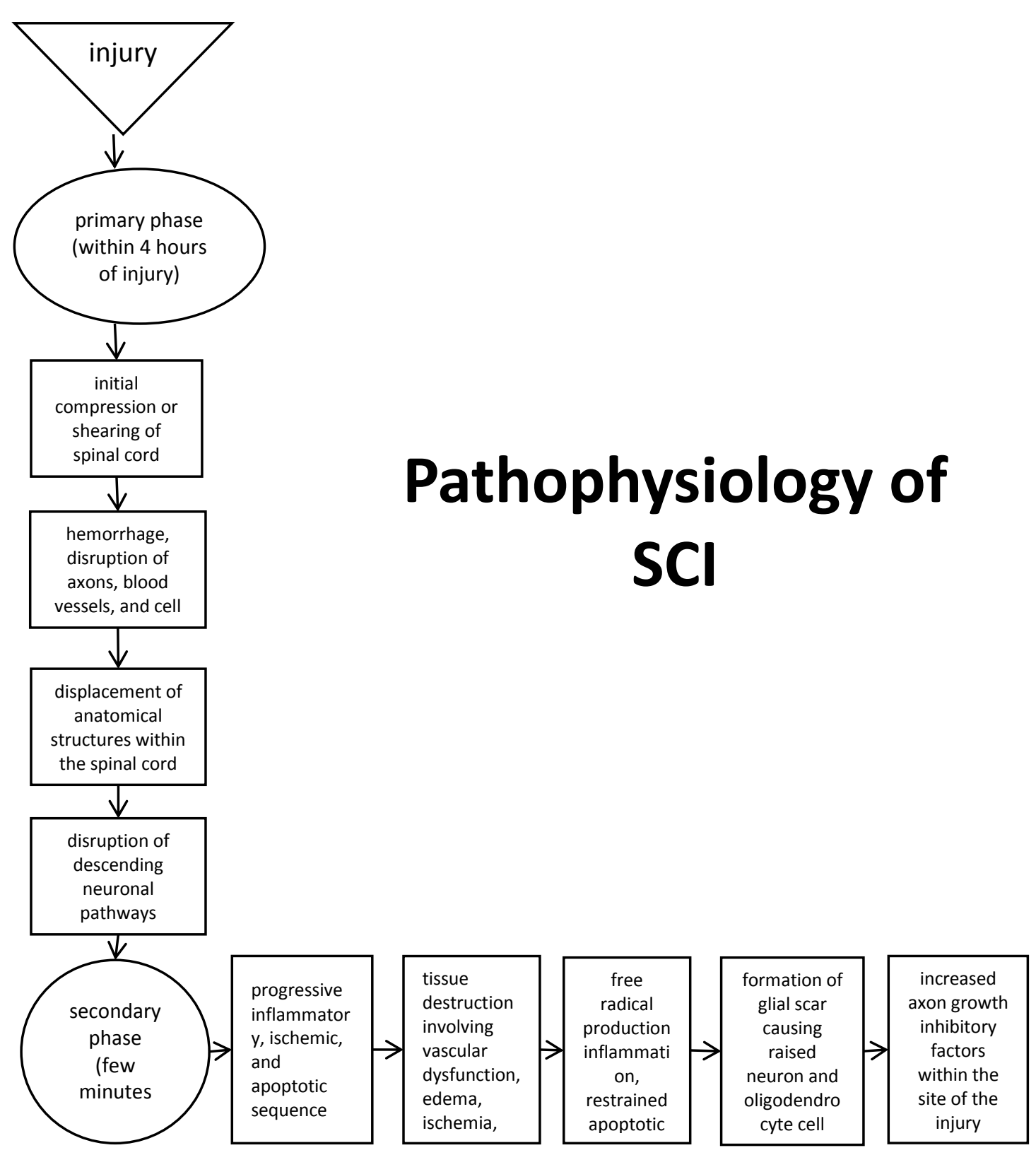

Figure 1: Outlines pathophysiology of $\mathrm{SCl}$ including primary and secondary phases $[3,11,12]$.

Several pharmacological treatments are offered for $\mathrm{SCl}$ patients. Riluzole is a neuroprotective drug that uses sodium channel blockade to prevent stimulation of glutamate receptors. Riluzolehas not been approved by the Food and Drug Administration (FDA) for $\mathrm{SCl}$, but a few clinical trials have been registered. Riluzole has demonstrated the ability to support neuroprotection and reduce excitotoxicity which leads to increased functional recovery at the injury site. Ketorolac is a non-steroidal antiinflammatory and potent analgesic drug that inhibits the cyclooxygenases. Ketorolac reduces neuronal death at the site of insult and reduces post-operative joint pain. Additional studies are required to transition to clinical practice. Minocycline is a neuroprotective agent for various neurodegenerative diseases including $\mathrm{SCl}$. Minocycline exerts anti-inflammatory actions through controlling the central nervous system (CNS) immune cells, regulating the levels of anti-inflammatory cytokines, and preventing 
neuroinflammation and cell death. Several clinical trials have been registered for this drug $[2,11]$.

Fingolimod is an agonist for sphingosine receptor modulator. Significant improvements of motor functions have been displayed through oral administration of this drug at the acute SCl injury, butdid not lessen early filtration of neutrophils and inflammatory cytokines in the spinal cord injury. Magnesium has been reported to demonstrate neuroprotective properties in neuronal cells by competing with calcium ions and being an endogenous calcium channel blocker. Magnesium supported improved motor function scores inanimal models with $\mathrm{SCl}$. Methylprednisolone is commonly used as an antioxidant and is an anti-inflammatory corticosteroid. Methylprednisolone improved blood flow of spinal cord by reducing lipid peroxidation and influx of calcium. Methylprednisolone has numerous adverse effects including pulmonary and gastrointestinal complications $[2,4,11,17]$ (Table 1).

\begin{tabular}{|c|c|}
\hline \multicolumn{2}{|c|}{ Pharmacological Based Treatments for $\mathrm{SCl}$} \\
\hline Pharmacological Intervention & Outcome for Patients with SCl \\
\hline Riluzole & $\begin{array}{l}\text { - } \\
\text { - } \\
\text { - } \\
\text { - } \\
\text { - } \\
\text { dew clinical trials registered } \\
\text { neuroprotective drug that prevents glutamate receptors } \\
\text { at injury site }\end{array}$ \\
\hline Ketorolac & $\begin{array}{l}\text { - } \\
\text { - } \quad \text { inhibits cyclooxygenases } \\
\text { - } \quad \text { reduces neuronal death at site of insult and reduces post- } \\
\text { operative joint pain } \\
\text { - long term studies required for translation to clinical } \\
\text { practice }\end{array}$ \\
\hline Minocycline & 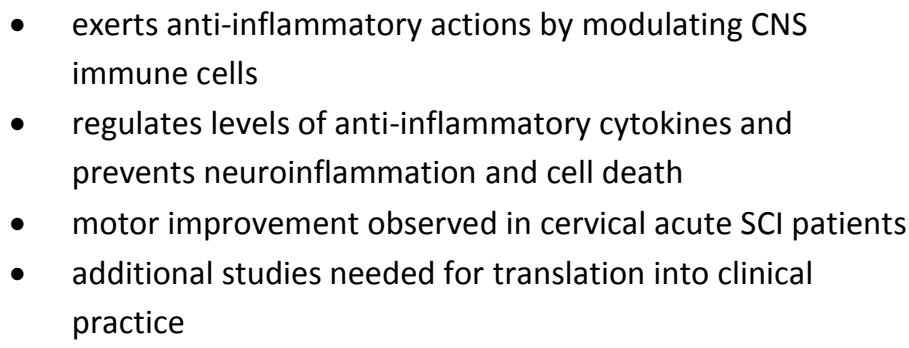 \\
\hline Fingolimod & 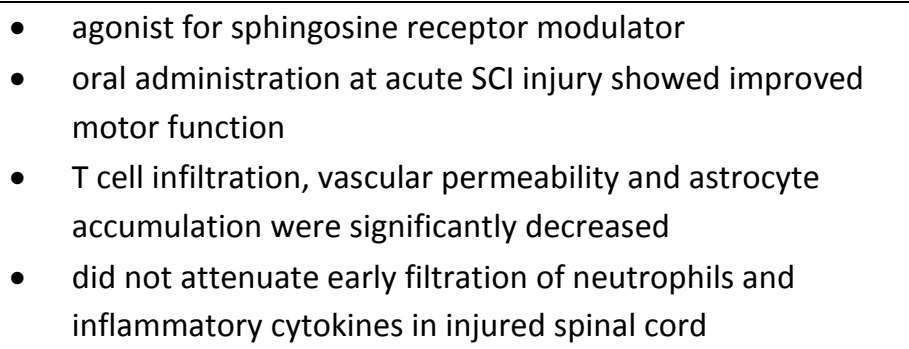 \\
\hline Magnesium & $\begin{array}{l}\text { - } \quad \text { antagonist for } \mathrm{N} \text {-methyl-D-aspartate receptor } \\
\text { - } \quad \text { supports neuronal cells by competing with calcium ions } \\
\text { and acts as endogenous calcium channel blocker }\end{array}$ \\
\hline
\end{tabular}




\begin{tabular}{|c|c|}
\hline & $\begin{array}{l}\text { - essential for neuronal cells to maintain cellular respiration, } \\
\text { membrane integrity, mRNA transcription, and energy } \\
\text { metabolism } \\
\text { - } \text { supported improved motor function scores in animal } \\
\text { model with } \mathrm{SCl}\end{array}$ \\
\hline Methylprednisolone & $\begin{array}{l}\text { - } \text { anti-inflammatory corticosteroid } \\
\text { - } \quad \text { commonly used as antioxidant } \\
\text { improved blood flow of spinal cord by reducing influx of } \\
\text { - } \quad \text { falcium and decreasing lipid peroxidation } \\
\text { - } \quad \text { numerous adverse effects including pulmonary and } \\
\text { gastrointestinal complications }\end{array}$ \\
\hline
\end{tabular}

Table 1: Shows variety of pharmacological treatment options and outcomes for patients with $\mathrm{SCl}$ [2].

Surgical intervention options for $\mathrm{SCl}$ patients are somewhat limited. Decompression of compressed discs along with surgical stabilization of spinal fractures within 24 hours after injury increased post-operative motor and sensory functions. Early decompression surgery has been shown to lower the risk of respiratory failure and sepsis, but neurosurgery for $\mathrm{SCl}$ patients is associated with high complications including durotomy and meningitis $[2,11]$. Tendon transfer surgery is an option for SCl patients with quadriplegia or tetraplegia. Benefits of tendon transfer surgery through improved hand functions for pinch force and functional activities have been reported for juvenile $\mathrm{SCl}$ patients [2].

Stem cell transplant procedures show promising potential as a treatment for SCl. Several different types of cells including stem cells (neural stem cell, mesenchymal stem cells, embryonic stem cells) and mature somatic cells (oligodendrocytes, Schwann cells, astrocytes, and olfactory sheathing cells) have been used for cell transplantation therapy procedures [2].

Neural stem cells (NSCs) exist within the CNS located within a subventricular and subgranular zones of the brain. NSCs have tripotential capability (neurons, astrocytes, and oligodendrocytes), maintain capacity for self-renewal, generate differentiated progeny that can functionally integrate and repair damaged CNS, and protect against excitotoxicity. NSCs are more limited in numbers and divide less frequently than embryonic stem cells (ESCs) [2,15,18-20]. ESCs possess the maximal capacity of differentiation and supported remyelination of neurons in the injured spinal cord. ESCs also demonstrated improvement of locomotory and sensory function without adverse effects. ESCs can be grown in unlimited quantities as they retain normal cell cycle signaling and do not undergo the process of senescence $[2,11,15,21]$. Mesenchymal stem cells (MSCs), bone marrow mononuclear cells and umbilical cord blood are sources for stem cells [22]. MSCs demonstrate the capability to differentiate into distinct cell lineages and have shown improved sensorimotor functions and reduced inflammatory response $[2,15,23-26]$.

Oligodendrocytes are a subtype of glia cells that support myelination within the CNS. Oligodendrocytes have demonstrated reduced pathogenesis of the lesion and improved motor function. Oligodendrocytes 
release neurotrophic factors which assist the survival of damaged neurons and encourage axonal regeneration andalso support functional recovery [2,27]. Astrocytes are non-neuronal cells and provide structure and physiological functions specifically at the synaptic junctions of the neuronal network. Their primary functions include synaptic transmission, antioxidant functions, blood-brain barrier formation, control of cerebral blood flow, secretion of neurotrophic factors, regulation of extracellular ions, and clearance of glutamate [2]. Astrocytes have demonstrated axonal growth and improved neuronal survival $[16,28,29]$. However, transplanted astrocytes around the lesion site have been reported to persist for a short period of time, and the formation of glial scars in CNS has led to reduced use of astrocytes for $\mathrm{SCl}[30]$.

Schwann cells (SCs) are myelin-forming cells for nerve fibers that are found within the peripheral nervous system. SCs have demonstrated the ability to provide neuroprotective effect, support axonal outgrowth, initiate remyelination process, reduce pseudocyst formation, and improve sensory and locomotory functions. SCs effect for repair is not sufficient to promote axonal response supporting complete motor function recovery. Olfactory ensheathing cells are support cells that wrap olfactory axons, support regeneration, and allow neurons to cross a glial scar. Combination of SCs and olfactory ensheathing cells togethershowed improved remyelination activity, regeneration abilities, and improved functional recovery as compared with singular transplant groups $[2,5,15,31]$.

\begin{tabular}{|c|c|}
\hline \multicolumn{2}{|r|}{ Stem Cell Treatments for SCI } \\
\hline Type of Stem Cell & Function of Stem Cell \\
\hline neural stem cell (NSC) & $\begin{array}{l}\text { - } \\
\text { exist within CNS located within subventricular and } \\
\text { - } \quad \text { tripotential capability (neurons, astrocytes and } \\
\text { oligodendrocytes } \\
\text { - } \text { maintain capacity for self-renewal } \\
\text { - } \text { generate differentiated progeny that integrate and repair } \\
\text { damaged CNS } \\
\text { - } \quad \text { protect against excitotoxicity } \\
\text { more limited in numbers and divide less frequently than } \\
\text { embryonic stem cells }\end{array}$ \\
\hline embryonic stem cell (ESC) & $\begin{array}{l}\text { - } \text { possess maximal capacity of differentiation } \\
\text { - } \quad \text { support remyelination of neurons in the injured spinal cord } \\
\text { - } \text { demonstrated improvement of locomotory and sensory } \\
\text { - } \quad \text { canction without adverse effects } \\
\text { - } \quad \text { retain normal cell cycle signaling and do not undergo } \\
\text { process of senescence }\end{array}$ \\
\hline mesenchymal stem cell (MSC) & $\begin{array}{l}\text { - sources are bone marrow mononuclear cells and umbilical } \\
\text { cord blood } \\
\text { - demonstrate ability to differentiate into distinct cell } \\
\text { lineages } \\
\text { - showed improved sensorimotor functions }\end{array}$ \\
\hline
\end{tabular}




\begin{tabular}{|c|c|}
\hline & - demonstrated reduced inflammatory response \\
\hline oligodendrocytes & $\begin{array}{l}\text { - } \text { subtype of glia cells that support myelination within CNS } \\
\text { - demonstrated reduced pathogenesis of lesion and improved } \\
\text { function } \\
\text { release neurotrophic factors that help survival of damaged } \\
\text { neurons } \\
\text { promote axonal regeneration and support functional } \\
\text { recovery }\end{array}$ \\
\hline astrocytes & $\begin{array}{l}\text { - } \text { non-neuronal cells that provide structure and physiological } \\
\text { functions at synaptic junctions of neuronal network } \\
\text { assist with synaptic transmission, control of cerebral blood } \\
\text { flow, blood-brain barrier formation, regulation of } \\
\text { extracellular ions, antioxidant functions, secretion of } \\
\text { neurotrophic factors and clearance of glutamate } \\
\text { - demonstrated axonal growth and improved neuronal } \\
\text { - } \quad \text { transival } \\
\text { persist and formations of glial scars in CNS has led to } \\
\text { decreased use of astrocytes for SCl }\end{array}$ \\
\hline Schwann cells (SC) & 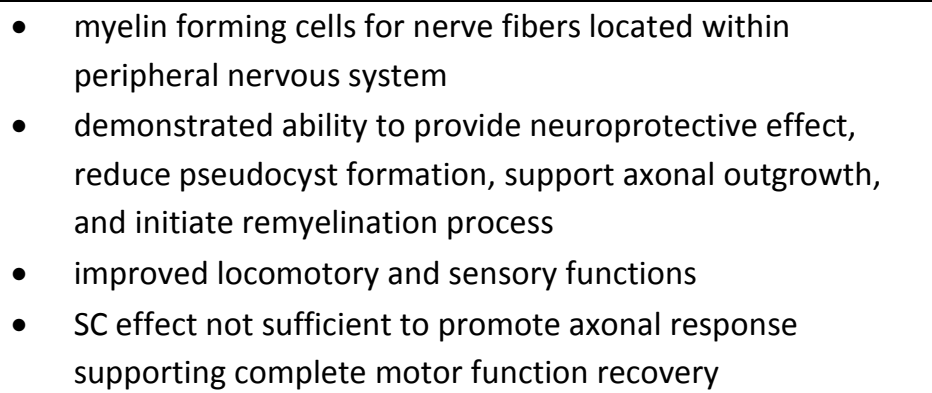 \\
\hline olfactory ensheathing cells & $\begin{array}{l}\text { - } \\
\text { - } \\
\text { - } \\
\text { support cells that wrap olfactory axons } \\
\text { showed ination of SC and olfactory ensheathing cells together } \\
\text { abilities and improved functional recovery }\end{array}$ \\
\hline
\end{tabular}

Table 2: Shows types of stem cells currently used for treatment and functions of each stem cell $[2,15]$.

Therapeutic adjunct options including immunotherapies, biomaterial scaffolds, and hydrogels may support additional regeneration of the spinal through augmenting stem cell survival, engraftment, and growth. Immunotherapy has shown opportunity for treatment of $\mathrm{SCl}$ through the control of molecular signals and through the environment regulation of the spinal cord injury. Antibodies targeting inhibitory muscles supported increased locomotion function after injury [10]. Additional studies investigated decreasing injury inflammation through utilization of B-cell depleting antibodies. Results indicated inflammatory signaling, dysfunction of hind limb, and reduction of cell death. Safety for patients must be demonstrated before these therapies are transitioned to patients. Antibodies must be tested to ensure that healthy myelin is not attacked or result in negative immunological responses [10]. Scaffolds and 
injectable hydrogels have been utilized to promote improved recovery for $\mathrm{SCl}$. Scaffolds and hydrogels have demonstrated improved cell survival and proliferation, increased oligodendrocyte progenitor cell migration, decreased teratoma formation, reduced inflammatory responses, decreased glial scar formation, and improved functional recovery post SCI [10,32].

Lithium has been used for many years as a treatment for manic depression and was one of the first drugs approved by United States Food and Drug Administration (FDA) in the early 1970s. Lithium is one of the lightest elements as an alkali metal and is the same family as sodium and potassium. Patients treated with lithium showed lymphopenia, reduced blood lymphocyte counts, granulocytosis,and increased white blood cell counts [33]. Scientists started to apply lithium to bone marrow stem cells and found that lithium affected phosphorylated inositides, which is a intracellular messenger system. Lithium also stimulated and inhibited phosphokinases and phosphatases, which inhibited glycogen synthetase kinase 3- $\beta$ (GSK3 $\beta$ ) enzyme. GSK3 $\beta$ inhibited glycogen synthetase enzyme which converts glucose to glycogen. GSK3 $\beta$ phosphorylates nuclear factors which includes activation of $T$ cells and WNT/B-catenin. GSK3 $\beta$ appeared to control cellular growth, protection, and differentiation of stem cells [33].

Lithium has demonstrated the ability to reduce lymphocyte count, increase total leukocyte and neutrophil counts, and increase erythrocyte counts and hematocrit in animal studies [34]. Lithium also increased pluripotent and committed stem cell colonies and showed an increase in differentiation toward granulocytosis [35]. Lithium is a strong stimulant of bone marrow stem cells and used after radiation therapy, chemotherapy, and toxin-induced neutropenia. Lithium has been shown to be neuroprotective for stroke and other neurodegenerative diseases in animal models. Lithium has a significant impact on cells and appears to turn on multiple cellular mechanisms and genes that protect cells against stress, toxins, injury, and ischemia $[33,36]$.

\section{Discussion}

\section{Trialsin animals}

Researchers have investigated the effectiveness of stem cells and lithium in animal models. Several clinical trials have been completed for the use of stem cells on human subjects and a few clinical trials are in the pre-recruitment stage for introducing the combination of lithium and stem cells for humans.

Su et al., in 2007 investigated the effect of lithium on the survival, proliferation, and differentiation of spinal cord derived neural progenitor cells (NPCs) transplanted into spinal cords of animal subjects. Results showed lithium increased proliferation of NPCs at 2 weeks after grafting and neuronal generation by NPCs at 2 weeks and 4 weeks after grafting. Lithium was not found to cause differentiation of NPCs into astrocytes or oligodendrocytes in vitro and post transplantation. Results indicated treatment with lithium up to a maximum of 4 weeks reduced microglia and macrophage activation which in turn, can reduce host immune reaction [37]. An additional study by Su et al,. in 2009 researched the effect lithium has on development neural progenitor cells (NPCs) derived from the spinal cord in vitro and after transplanted in vivo in animal subjects. Results indicated lithium increased proliferation and neuronal differentiation of NPCs in vitro. Lithium treatment significantly increased 
expression and production of brain-derived neurotrophic factor by NPCs in culture. Lithium was able to elevate neuronal generation and brain-derived neurotrophic factor production of NPCs after transplantation highlighting the potential of lithium in cell replacement strategies in the treatment of spinal cord injury [38].

Another study conducted by Deng et al., in 2010 investigated the effects of lithium chloride in combination with human umbilical cord blood mesenchymal stem cell (hUCB-SCs) transplantation in animal models. Animal subjects were randomly assigned to 4 groups: control group, lithium chloride group, hUCB-SCs group, and hUCB-SCs(+) lithium chloride group. Motor function of the animal hindlimbs was evaluated postoperatively on days 1 and 3 and the last days of the following weeks. There were improved motor function results for hUCB-SCs(+) lithium chloride group 8 weeks postoperatively as well as distribution and regeneration of spinal nerve fibers that were observed through fluorescent-gold spinal cord retrograde tracing. Researchers concluded lithium chloride in combination with hUCB-SCS improves functional recovery of hind limbs in animal models [39].

A study evaluated by Tsai et al., in 2011 researched efficiency of mesenchymal stem cells (MSC) combined with Valproate and lithium to improve outcomes of cerebral ischemia in animal models. In this study, MSC primed with Valproate and/or lithium chloride was transplanted into animal subjects 24 hours after transient middle cerebral artery occlusion. Results indicated priming MSC with Valproate and lithium increased the number of MSC homing and migration ability of MSC, reduced infarct volume of the brain, and improved functional recovery. This study supports the use of lithium combined with MSCs to treat neurological impairments [40].

Dong et al., in 2015 also researched the efficacy of lithium to mesenchymal stem cells (MSC) proliferation and neural differentiation in vitro and after transplantation in vivo in animal subjects. MSCs can be harvested from a large variety of tissues including: bone marrow, synovium, skeletal muscle, adipose tissue, and umbilical cord blood. While MSCs are reported to be easy to harvest and culture, only a small proportion of transplanted MSCs are reported to survive, and few cells differentiate into mature neural phenotypes. Additional pharmacological options were explored. Lithium was found to promote proliferation and neural differentiation of green fluorescent protein MSCs. After transplantation, lithium treatment improved cell survival and neural differentiation into more astrocytes, oligodendrocytes, and neurons promoting neural regeneration. These results support the use of lithium to augment efficiency of MSCs transplantation in central nervous system disorders [41]. In a study conducted by Zhang, et al.,in 2018, NSCs were injected into the tibial nerve and then transplanted into the spinal cord of animal models to look at the effects of lithium chloride on the survival of spinal neurons, axonal regeneration, and functional recovery. Results indicated that combining tibial nerve transplantation with NSCs and lithium chloride (LiCl) injection resulted in improved host motoneurons surviving in the spinal cord,less glial scar area, more regenerated axons in tibial nerve, and decreased macrosialin expression. This research team concluded that lithium may demonstrate therapeutic benefit in cell replacement for central nervous system injury as a result of its ability to improve neuronal generation and survival for grafted NSCs and reduced host immune reaction [42]. 
An additional study by Zhang et al., in 2019 examined the effects of lithium chloride on cell viability, cell dynamics, proliferation, and NSC differentiation. Wht signaling pathway was also explored. The researchers showed that lithium chloride promoted proliferation of NSCs through the Wnt signaling pathway being triggered. Lithium supported long term neuroprotective effects by triggering of the Wnt signaling pathway in order to promote NSC proliferation and survival. This provides new treatment for neurodegenerative diseases involved with NSC proliferation. This research suggests lithium chloride can show positive results for targeting NSCs specifically for neurogenerative diseases and bipolar affective disorder [43].

A study by Mohammadshirazi, et al., in 2019 investigated whether the combination of human neural stem cells hNSCs with lithium chloride (Li) improved cell survival, proliferation, and differentiation in animal models. Experimental groups included: control group, hNSCs transplanted group, lithium group, and hNSCs and lithium combined group. Locomotor activity scores and motor evoked potentials were performed to evaluate motor recovery. Researchers found that intraperitoneal injection of lithium chloride for 2 weeks led to locomotor improvement 3 weeks after $\mathrm{SCl}$, as compared to the control group. The results of this study suggested the injured environment may have inflammation even after cell transplantation. This inflammation is not suppressed by cyclosporine injection. Researchers summarized that lithium leads to improved spinal cord injury treatment individually or in combination with neural stem cell transplantation. Researchers further expressed that animals would show greater improvement if inflammation was controlled [44] (Table 3).

\begin{tabular}{|c|c|c|c|c|c|c|}
\hline \multicolumn{7}{|c|}{ Stem Cell Human SCl Clinical Trials } \\
\hline Trial Name & Status & Intervention & $\mathbf{N}$ & $\begin{array}{l}\text { Subject } \\
\text { Age } \\
\text { (Years) }\end{array}$ & $\begin{array}{l}\text { AIS } \\
\text { Scale }\end{array}$ & $\begin{array}{l}\text { Time from } \\
\text { Injury }\end{array}$ \\
\hline $\begin{array}{l}\text { Umbilical Cord Blood Cell } \\
\text { Transplant into Injured } \\
\text { Spinal Cord with Lithium } \\
\text { Carbonate or Placebo } \\
\text { Followed by Locomotor } \\
\text { Training }\end{array}$ & $\begin{array}{l}\text { pre- } \\
\text { recruitment }\end{array}$ & $\begin{array}{l}\text { umbilical cord blood } \\
\text { mononuclear stem } \\
\text { cells, lithium } \\
\text { carbonate }\end{array}$ & 27 & $18-60$ & A & $\begin{array}{l}>12 \\
\text { months }\end{array}$ \\
\hline $\begin{array}{l}\text { Safety Study of Human } \\
\text { Spinal Cord-derived } \\
\text { Neural Stem Cell } \\
\text { Transplantation for } \\
\text { Treatment of Chronic SCl }\end{array}$ & recruiting & $\begin{array}{l}\text { human spinal cord- } \\
\text { derived neural stem } \\
\text { cell }\end{array}$ & 8 & $18-65$ & A & $1-2$ years \\
\hline $\begin{array}{l}\text { Stem Cell Spinal Cord } \\
\text { Injury Exoskeleton and } \\
\text { Virtual Reality Treatment } \\
\text { Study (SciExVR) }\end{array}$ & recruiting & $\begin{array}{l}\text { autologous bone } \\
\text { marrow derived } \\
\text { stem cells }\end{array}$ & 40 & $>18$ & A-D & $N R$ \\
\hline $\begin{array}{l}\text { Adipose Stem Cells for } \\
\text { Traumatic Spinal Cord } \\
\text { Injury (CELLTOP) }\end{array}$ & $\begin{array}{l}\text { active, not } \\
\text { recruiting }\end{array}$ & $\begin{array}{l}\text { autologous, adipose } \\
\text { derived } \\
\text { mesenchymal stem } \\
\text { cells }\end{array}$ & 10 & $>18$ & $A-B$ & $\begin{array}{c}2 \text { weeks - } \\
1 \text { year }\end{array}$ \\
\hline $\begin{array}{l}\text { Dose Escalation Study of } \\
\text { AST-OPCI in Spinal Cord }\end{array}$ & completed & $\begin{array}{l}\text { human embryonic } \\
\text { stem cell derived }\end{array}$ & 25 & $18-69$ & $A-B$ & $21-42$ days \\
\hline
\end{tabular}

Research Article | Gallicchio VS, et al. J Stem Cell Res 2020, 1(2)-15. 


\begin{tabular}{|c|c|c|c|c|c|c|}
\hline Injury & & $\begin{array}{l}\text { oligodendrocyte } \\
\text { progenitor cells }\end{array}$ & & & & \\
\hline $\begin{array}{l}\text { Clinical Trial Assessing } \\
\text { Safety and Efficacy of } \\
\text { Umbilical Cord Blood } \\
\text { Mononuclear Cell } \\
\text { Transplant Therapy of } \\
\text { Chronic Complete Spinal } \\
\text { Cord Injury }\end{array}$ & completed & $\begin{array}{l}\text { umbilical cord blood- } \\
\text { derived mononuclear } \\
\text { cells, } \\
\text { methylprednisolone, } \\
\text { and lithium } \\
\text { carbonate }\end{array}$ & 28 & $29-53$ & $A-D$ & $2-20$ years \\
\hline
\end{tabular}

Table 3: Shows current human clinical trials for stem cell treatments with spinal cord injury. Studies included are in the pre-recruitment, recruitment, active, and completed phases $[6,45]$.

Platt et al., in 2020 reviewed current human clinical trials for stem cell treatments with spinal cord injury within the United States. They included current studies in pre-recruitment, recruitment, active and completed research studies.

A human research clinical trial currently in pre-recruitment stage will evaluate the effectiveness umbilical cord blood mononuclear stem cells combined with lithium carbonate injected above and below the area of spinal cord injury into bilateral dorsal root entry zones at least 1 year post injury. Twenty seven patients will be recruited into this study and randomly assigned to three groups: control group, stem cell transplantation group, and stem cell transplantation and lithium group [6].

An additional human research clinical trial in the recruitment stage sponsored by Seneca Biopharma Inc.is assessing stereotactic human spinal cord derived stem cell injections and adverse events and lab abnormalities found within the first six months after injection. Eight patients will be enrolled in this study 1 to 2 years post injury including 4 patients with injuries to the thoracic spine (T2-T12) and 4 patients with injuries to lower cervical spine (C5-C7). Results for the first four patients with thoracic spinal cord injury are promising. One and two levels of neurological improvement was shown by two patients and in the first 18-27 months post stem cell injections, no serious adverse events were reported [6].

The next human research clinical trial in recruitment stage is evaluating transplantation of autologous bone marrow derived stem cells. Forty patients will be recruited for this study and will receive bilateral para spinal injections of cells at the level of injury and will also receive injections superior and inferior to the spinal segment. Patients will receive intranasal placement of additional stem cells and intravenous injection. Three treatment arms will be established for this study: treatment only group, treatment + exoskeleton movement group, and treatment + virtual reality visualization group [6].

A human research clinical trial in the active stage sponsored by CELLTOP is investigating intrathecal injection of mesenchymal stem cells. Patients from 2 weeks to 1 year post injury are included in this trial. The first treated patient was involved in a surfing accident and reported an initial spinal cord injury score of AIS A and showed improvement to AIS C before enrollment in this study. After enrollment in the study, the patient did not report any safety issues adverse events during the first 18 months. 
Additionally, the patient demonstrated improvement in sensory and motor scores during the initial follow up period [6].

A human research clinical trial in the completed stage evaluated dose escalation of stereotactic injections of human embryonic stem cell derived oligodendrocyte progenitor cells. Patients enrolled in this study were AIS A or AIS B spinal cord injuries and 21-42 days post injury. Patients received either two injections of 10 million cells or one injection of 2 million or 10 million cells. Outcomes measured for this study include the number of adverse events that occurred within one year of injection. No significant adverse events have been reported, but full results from this study have not been published yet. Also, sponsoring industry for this study reported two-thirds of the patients demonstrated significant improvement and that data is not yet published in peer reviewed literature [6].

Outside of the United States, Zhu et. al., in 2016 investigated28 patients in Hong Kong and Kumming that underwent umbilical cord blood derived mononuclear cell transplantation (UCB-MNC) following complete spinal cord injury. The 8 patients in Hong Kong study underwent injections of 4-8 $\mu 1$ of UCBMNCs into the spinal cord above and below the injury site. These patients did not demonstrate recovery of motor function. The 20 patients treated in Kumming were assigned to five groups: 4, 8, and $16 \mu l$ of UCB-MNCs, 16 ul of UCB-MNCs + methylprednisolone, or $16 \mu$ of UCB-MNCs + methylprednisolone + 6week course of oral lithium carbonate. There was 3-6 months of intensive locomotor training completed by all patients. Prior to surgery, only 2 patients could walk $10 \mathrm{~m}$ with assistance. At a year post USC-MNC transplantation, $15 / 20$ patients walked $10 \mathrm{~m}$ and 12/20 patients did not require assistance with bladder or bowel management. Five patients converted from complete $\mathrm{SCl}$ to incomplete $\mathrm{SCl}$. Locomotor training also improved independence for activities of daily living including self-care, bowel and bladder management, and mobility [45]. Results of this study were inconclusive in regard to the effect of methylprednisolone and lithium. Only two of eight patients that received UCB-MNCs + methylprednisolone + lithium recovered walking, compared to eight of eight patients in the other groups that were injected with $8+16 \mu l$ of UCB-MNCs. Lithium was reported to decrease neuropathic pain for 2 patients. Of note, for the group that was treated with UCB-MNCs + methylprednisolone + lithium, one patient received placebo instead of lithium tablets, one patient was already walking when the trial began, and one patient discontinued walking training due to swelling of the knee. Overall, only one patient in this group represented a valid comparison with the patients that were only injected with UCB-MNCs. Additional clinical trials are needed to further investigate the effects of lithium [45] (Table 4).

\begin{tabular}{|c|c|c|}
\hline \multicolumn{3}{|c|}{ American Spinal Injury Association (ASIA) Impairment Scale } \\
\hline ASIA Grade & Description & \\
\hline A & Complete & no sensory or motor function persists in sacral segments S4-S5 \\
\hline B & Incomplete & $\begin{array}{l}\text { sensory and not motor function remains below neurological level, including } \\
\text { sacral segments S4-S5 }\end{array}$ \\
\hline C & Incomplete & $\begin{array}{l}\text { motor function pertained below neurological level and more than half of key } \\
\text { muscles below neurological level possess muscle grade less than } 3\end{array}$ \\
\hline D & Incomplete & $\begin{array}{l}\text { motor function restored below neurological level and at least half of key } \\
\text { muscles below neurological level have muscle grade greater than or equal to }\end{array}$ \\
\hline
\end{tabular}




\begin{tabular}{|c|c|c|}
\hline & & 3 \\
\hline$E$ & Normal & sensory and motor functions remain normal \\
\hline
\end{tabular}

Table 4: Shows American Spinal Injury Association (ASIA) Impairment Scale used for patients with SCI. Lists ASIA grades and descriptions for each grade [2].

\section{Conclusion}

Current treatment for $\mathrm{SCl}$ includes the use of stem cell transplantation in both animal and human subjects. Researchers have found combination of stem cell transplantation and lithium has demonstrated improved functional outcomes in animal models including: increased proliferation of NPCs, reduced host immune reaction, improved cell survival, and accelerated functional recovery of limbs. Human subject trials for stem cell transplantation have shown: increased remyelination activity, increased axonal growth, improved neuronal survival, reduced inflammatory responses, and improved sensory and locomotor function. Several research teams are currently in the process of evaluating the efficacy of stem cell transplantation combined with lithium for human subjects. Several human trials are in the pre-recruitment and recruitment stages. One human trial in the active stage reported improvement for motor and sensory skills for the initial patient. An additional human studies trial in the completed stage reported improvement for two-thirds of the patients. One study completed with 20 human subjects showed inconclusive results. Researchers believe the use of stem cells combined with lithium may offer alternative options to patients with $\mathrm{SCl}$. Additional research trials are needed to further investigate the functional effects and efficacy for lithium combined with stem cell transplantation for human patients with $\mathrm{SCl}$.

\section{References}

1. Ashammakhi N, Kim HJ, Ehsanipour A, Bierman RD, Kaarela OX, et al. (2019) Regenerative Therapies for Spinal Cord Injury. Tissue Eng. Part B Rev. 25(6):471-91.

2. Venkatesh K, Ghosh SK, Mullick M, Manivasagam G, Sen D. (2019) Spinal cord injury: pathophysiology, treatment strategies, associated challenges, and future implications. CELL TISSUE RES. 1:1-27.

3. Lin L, Lin H, Bai S, Zheng L, Zhang X. (2018) Bone marrow mesenchymal stem cells (BMSCs) improved functional recovery of spinal cord injury partly by promoting axonal regeneration. Neurochem Int. 115:804.

4. Nejati Koshki K, Mortazavi Y, Pilehvar Soltanahmadi Y, Sheoran S, Zarghami N. (2017) An update on application of nanotechnology and stem cells in spinal cord injury regeneration. Biomed Pharmacother. 90:85-92.

5. Tsuji O, Sugai K, Yamaguchi R, Tashiro S, Nagoshi N, et al. (2019) Concise review: laying the groundwork for a first-in-human study of an induced pluripotent stem cell-based intervention for spinal cord injury. Stem Cells. 37(1):6-13.

6. Platt A, David BT. (2020) Stem Cell Clinical Trials in Spinal Cord Injury: A Brief Review of Studies in the United States. Medicines. 7(5):27.

7. Muheremu A, Peng J, Ao Q. (2016) Stem cell based therapies for spinal cord injury. Tissue \& cell. 48(4):328-33. 
8. (2016) National Spinal Cord Injury Statistical Center. Spinal cord injury (SCI) facts and figures at a glance. Birmingham, AL: University of Alabama at Birmingham. 39(3):370-71.

9. Kumar R, Lim J, Mekary RA, Rattani A, Dewan MC, et al. (2018). Traumatic Spinal Injury: Global Epidemiology and Worldwide Volume. World neurosurg. 113: e345-e363.

10. Jin MC, Medress ZA, Azad TD, Doulames VM, Veeravagu A. (2019) Stem cell therapies for acute spinal cord injury in humans: a review. Neurosurg focus. 46(3):E10.

11. Gazdic M, Volarevic V, Harrell CR, Fellabaum C, Jovicic N, (2018). Stem cells therapy for spinal cord injury. Int J Mol Sci.19(4):1039.

12. Shao A, Tu S, Lu J, Zhang J. (2019) Crosstalk between stem cell and spinal cord injury: pathophysiology and treatment strategies. Stem Cell Res Ther. 10(1):238.

13. Gazdic M, Volarevic V, Arsenijevic A, Erceg S, Moreno-Manzano V, (2017) Stem cells and labeling for spinal cord injury. Int J Mol Sci. 8(1):6.

14. Zhang J, Li S, Wu Y. (2017) Recovery of spinal cord injury following electroacupuncture in rats through enhancement of Wnt/ $\beta$-catenin signaling. Mol Med Rep. 16(2):2185-190.

15. Coutts M, Keirstead HS. (2008) Stem cells for the treatment of spinal cord injury. Experiment Neurol. 209(2):368-77.

16. Karimi Abdolrezaee S, Eftekharpour E. (2012) Stem cells and spinal cord injury repair. Adv. Experiment Med Biol. 760:53-73.

17. Ye J, Qin Y, Tang Y, Ma M, Wang P. (2018) Methylprednisolone inhibits the proliferation of endogenous neural stem cells in nonhuman primates with spinal cord injury. J Neurosurg. 29(2):199-207.

18. Stenudd M, Sabelstrom H, Frisén J. (2015). Role of endogenous neural stem cells in spinal cord injury and repair. JAMA neurol. 72(2):235-37.

19. Kumamaru H, Kadoya K, Adler AF, Takashima Y, Graham L. (2018) Generation and post-injury integration of human spinal cord neural stem cells. Nat methods. 15(9):723-31.

20. Csobonyeiova M, Polak S, Zamborsky R, Danisovic L. (2019) Recent Progress in the Regeneration of Spinal Cord Injuries by Induced Pluripotent Stem Cells. Int J Mol Sci. 20(15):3838.

21. Damdimopoulou P, Rodin S, Stenfelt S, Antonsson L, Tryggvason K, et al. (2016) Human embryonic stem cells. Best practice \& research. Clin Obstet Gynecol. 31, 2-12.

22. Hakim R, Covacu R, Zachariadis V, Frostell A, Sankavaram SR, et al. (2019) Mesenchymal stem cells transplanted into spinal cord injury adopt immune cell-like characteristics. Curr Stem Cell Res Ther. 10(1):115.

23. Cofano F, Boido M, Monticelli M, Zenga F, Ducati A, et al. (2019) Mesenchymal Stem Cells for Spinal Cord Injury: Current Options, Limitations, and Future of Cell Therapy. Int J Mol Sci. 20(11):2698.

24. Shende P, Subedi M. (2017) Pathophysiology, mechanisms and applications of mesenchymal stem cells for the treatment of spinal cord injury. Biomed Pharmacother. 91:693-706.

25. Kim HY, Kumar H, Jo MJ, Kim J, Yoon JK. (2018) Therapeutic Efficacy-Potentiated and Diseased OrganTargeting Nanovesicles Derived from Mesenchymal Stem Cells for Spinal Cord Injury Treatment. Nano letters. 18(8):4965-75.

26. Park K. (2018) Functional recovery in spinal cord injury using mesenchymal stem cells. J CONTROL RELEASE. 278:159.

27. Ramadan WS, Abdel-Hamid GA, Al-Karim S, Zakar NA, Elassouli MZ. (2018) Neuroectodermal stem cells: A remyelinating potential in acute compressed spinal cord injury in rat model. J Biosci. 43(5):897-909. 
28. Grégoire CA, Goldenstein BL, Floriddia EM, Barnabé-Heider F, Fernandes KJ. (2015) Endogenous neural stem cell responses to stroke and spinal cord injury. Glia. 63(8):1469-82.

29. Davies SJ, Shih CH, Noble M, Mayer-Proschel M, Davies JE, et al. (2011) Transplantation of specific human astrocytes promotes functional recovery after spinal cord injury. PloS one. 6(3):e17328.

30. Lukovic D, Stojkovic M, Moreno-Manzano V, Jendelova P, Sykova E. (2015) Concise review: reactive astrocytes and stem cells in spinal cord injury: good guys or bad guys? Stem cells. 33(4):1036-41.

31. Assinck P, Duncan GJ, Hilton BJ, Plemel JR, Tetzlaff W. (2017) Cell transplantation therapy for spinal cord injury. Nat neurosci. 20(5):637-47.

32. Agbay A, Edgar JM, Robinson M, Styan T, Wilson K, et al. (2016) Biomaterial Strategies for Delivering Stem Cells as a Treatment for Spinal Cord Injury. CTO. 202(1-2):42-51.

33. Young W. (2009) Review of lithium effects on brain and blood. Cell transplantation, 18(9):951-75.

34. Kanwar KC, Raina P. (1988) Heavy lithium ingestion and haematological changes in rats. Journal of environmental pathology, toxicology and oncology: official organ of the J Environ Pathol Toxicol Oncol. 8(7 Spec No):1-5.

35. Gallicchio VS, Chen MG. (1981) Influence of lithium on proliferation of hematopoietic stem cells. Experiment hematol. 9(7):804-10.

36. Ferensztajn-Rochowiak E, Rybakowski JK. (2016) The effect of lithium on hematopoietic, mesenchymal and neural stem cells. PR. 68(2):224-30.

37. Su H, Chu TH, Wu W. (2007) Lithium enhances proliferation and neuronal differentiation of neural progenitor cells in vitro and after transplantation into the adult rat spinal cord. Experiment neurol. 206(2):296-307.

38. Su H, Zhang W, Guo J, Guo A, Yuan Q, et al. (2009) Lithium enhances the neuronal differentiation of neural progenitor cells in vitro and after transplantation into the avulsed ventral horn of adult rats through the secretion of brain-derived neurotrophic factor. J Neurochem. 108(6):1385-98.

39. Deng XY, Zhou RP, Lu KW, Jin DD. (2010) Nan fang yi ke da xue xue bao. South Med J. 30(11):2436-39.

40. Tsai LK, Wang Z, Munasinghe J, Leng $Y$, Leeds $P$, et al. (2011) Mesenchymal stem cells primed with valproate and lithium robustly migrate to infarcted regions and facilitate recovery in a stroke model. Stroke. 42(10):2932-39.

41. Dong BT, Tu GJ, Han YX, Chen Y. (2015) Lithium enhanced cell proliferation and differentiation of mesenchymal stem cells to neural cells in rat spinal cord. Int J Clin Exp Pathol. 8(3):2473-83.

42. Zhang LQ, Zhang WM, Deng L, Xu ZX, Lan WB, et al. (2018) Transplantation of a Peripheral Nerve with Neural Stem Cells Plus Lithium Chloride Injection Promote the Recovery of Rat Spinal Cord Injury. Cell transplant. 27(3):471-84.

43. Zhang J, He L, Yang Z, Li L, Cai W. (2018) Lithium chloride promotes proliferation of neural stem cells in vitro, possibly by triggering the Wnt signaling pathway. Animal cells and systems. 23(1):32-41.

44. Mohammadshirazi A, Sadrosadat H, Jaberi R, Zareikheirabadi M, Mirsadeghi S, et al. (2019) Combinational therapy of lithium and human neural stem cells in rat spinal cord contusion model. J Cell Physiol. 234(11):20742-54.

45. Zhu H, Poon W, Liu Y, Leung GK, Wong Y, et al. (2016) Phase I-II Clinical Trial Assessing Safety and Efficacy of Umbilical Cord Blood Mononuclear Cell Transplant Therapy of Chronic Complete Spinal Cord Injury. Cell transplant. 25(11):1925-43.

This article was originally published in a special issue entitled "Regenerative medicine: clinical use of stem cells as therapies", handled by Editor. Prof. Dr. Vincent S. Gallicchio.

Research Article | Gallicchio VS, et al. J Stem Cell Res 2020, 1(2)-15. DOI: https://doi.org/10.52793/JSCR.2020.1(2)-12 